\title{
BMJ Open Open carpal tunnel release and diabetes: a retrospective study using PROMs and national quality registries
}

\author{
Malin Zimmerman, ${ }^{\oplus 1,2}$ Katarina Eeg-Olofsson,, ${ }^{3,4}$ Ann-Marie Svensson, ${ }^{5}$ \\ Mikael Åström, ${ }^{6}$ Marianne Arner, ${ }^{7,8}$ Lars Dahlin ${ }^{1,2}$
}

To cite: Zimmerman M, EegOlofsson K, Svensson A-M, et al. Open carpal tunnel release and diabetes: a retrospective study using PROMs and national quality registries. BMJ Open 2019;9:e030179. doi:10.1136/ bmjopen-2019-030179

- Prepublication history and additional material for this paper are available online. To view these files, please visit the journal online (http://dx.doi. org/10.1136/bmjopen-2019030179).

Received 05 March 2019 Revised 31 July 2019

Accepted 16 August 2019

Check for updates

(c) Author(s) (or their employer(s)) 2019. Re-use permitted under CC BY-NC. No commercial re-use. See rights and permissions. Published by BMJ.

For numbered affiliations see end of article.

Correspondence to

Dr Malin Zimmerman;

malin.zimmerman@med.lu.se

\section{ABSTRACT}

Objectives To study patient-reported outcome after open carpal tunnel release (OCTR) for carpal tunnel syndrome (CTS) in patients with or without diabetes using national healthcare quality registries.

Design Retrospective cohort study.

Setting Data from the Swedish National Quality Registry for Hand Surgery (HAKIR; www.hakir.se) were linked to data from the Swedish National Diabetes Register (NDR; www.ndr.nu).

Participants We identified 9049 patients (10770 hands) operated for CTS during the inclusion period (2010-2016). Primary outcome measures Patient-reported outcome measures were analysed before surgery and at 3 and 12 months postoperatively using the QuickDASH as well as the HAKIR questionnaire with eight questions on hand symptoms and disability.

Results Patients with diabetes $(n=1508 ; 14 \%)$ scored higher in the QuickDASH both preoperatively and postoperatively than patients without diabetes, but the total score change between preoperative and postoperative QuickDASH was equal between patients with and without diabetes. The results did not differ between patients with type 1 or type 2 diabetes. Patients with diabetic retinopathy scored higher in QuickDASH at 3 months postoperatively than patients with diabetes without retinopathy. In the regression analysis, diabetes was associated with more residual symptoms at 3 and 12 months postoperatively.

Conclusions Patients with diabetes experience more symptoms both before and after OCTR, but can expect the same relative improvement from surgery as patients without diabetes . Patients with retinopathy, as a proxy for neuropathy, may need longer time for symptoms to resolve after OCTR. Smoking, older age, higher HbA1c levels and receiving a diabetes diagnosis after surgery were associated with more residual symptoms following OCTR.

\section{INTRODUCTION}

The gold standard for treatment of carpal tunnel syndrome (CTS) is open carpal tunnel release (OCTR). The spectrum of risk factors leading to CTS is fairly well recognised, and includes female gender, diabetes and rheumatoid arthritis. ${ }^{1}$ Other concomitant hand conditions are associated with a smaller improvement in the Boston Carpal Tunnel

\section{Strengths and limitations of this study}

The major strength of this study is the large nationwide population size and the broad selection of patient-reported outcome measure variables that were analysed.

- The most prominent limitation is the low response rate of the questionnaires.

- The patient group that did not respond to any questionnaires were younger than the group that had responded, and our data did not allow any further detailed evaluation. These results are consistent with other data on patients who are lost to follow-up.

- Neuropathy is lacking in National Diabetes Register, which is why we chose to use retinopathy, where reliable data from fundus photography are available, as a proxy variable.

Questionnaire after OCTR. ${ }^{2}$ However, less is known about diabetes as a risk factor for an adverse surgical outcome. Previous studies on surgical outcome after OCTR in patients with diabetes have shown conflicting results; some showing no difference in outcome between patients with and without diabetes, ${ }^{3-5}$ whereas others have found less recovery, using various endpoints, in patients with diabetes. ${ }^{6-9}$ Study comparisons are difficult due to the lack of a gold standard in evaluating outcome after OCTR. Several patient-reported outcome measures (PROMs) have been developed for evaluating upper extremity disorders. The QuickDASH is widely utilised, including assessment of outcome after OCTR. ${ }^{1011}$

Mechanisms affecting peripheral nerves in diabetes are many, including microangiopathy, hypoxia and metabolic factors, ${ }^{12}$ rendering the diabetic nerve more sensitive to compression. ${ }^{13}$ Retinopathy is a frequent complication seen in diabetes, and there is an association between retinopathy and diabetic neuropathy, ${ }^{1415}$ as well as between ocular neurodegenerative changes and diabetic neuropathy. ${ }^{16} 17$ Retinopathy might hence be used as a proxy variable for neuropathy. Based 
on the results of a previous smaller study, ${ }^{11}$ we hypothesised that patient-reported outcome after OCTR is worse in patients with diabetes, and in particular in patients with diabetic neuropathy, than in patients without diabetes.

The implementation of a national quality registry for hand surgery (HAKIR; www.hakir.se) in Sweden in 2010 provided new opportunities for research on large datasets. Using the data available from HAKIR, ${ }^{18}$ linked with data from the Swedish National Diabetes Register (NDR; www.ndr.nu), the purpose of this study was twofold. First, we aimed to study patient-reported outcome after OCTR on a national level in Sweden, comparing patients with and without diabetes. Second, we aimed to study whether retinopathy and HbA1c levels had an influence on patient-reported outcome after OCTR.

\section{METHODS}

\section{Data sources}

HAKIR, launched in 2010, HAKIR, is a Swedish National Quality Registry for hand surgery procedures. All university hospitals (seven specialised hand surgery departments) and two private hand surgery units in Sweden register all performed operations on patients above 16 years of age in the registry. ${ }^{19}$ Each patient provides informed consent for inclusion in the registry. Coding of all procedures is registered. Before surgery and at 3 and 12 months postoperatively, patients are asked to fill in 8 Likert scale questions (HAKIR questionnaire-8; HQ-8) and the QuickDASH questionnaire, ${ }^{20}$ either by post or as an online survey. The HQ-8 questions are scored from 0 to 100 in 10 point increments and consists of questions assessing pain on load, pain on motion without load, pain at rest, stiffness, weakness, numbness/tingling in fingers, cold sensitivity and ability to perform daily activities. The Swedish translated version of the QuickDASH is also used. ${ }^{20}$ The QuickDASH adds up to a total score of $0-100^{21}$. All OCTRs, due to primary CTS (KKÅ97 operation code ACC51, ${ }^{22}$ ICD-10 diagnosis code G560) ${ }^{23}$ registered in HAKIR between 2010 and 2016, were included. OCTR was accepted for inclusion when the code G560 was the primary or secondary, but not as a tertiary diagnosis. OCTR performed due to other causes than primary CTS were excluded.

The Swedish NDR is a nationwide quality register and includes patients with diabetes aged $\geq 18$ years and provides information on type of diabetes, risk factors, diabetic complications and medications. ${ }^{24} 25$ Patient data are continuously reported via electronic patient records from the clinic, or registered directly online to the NDR. ${ }^{26}$ Each patient provides informed consent for inclusion in the register. Information on type of diabetes, diabetes duration, HbA1c levels, body mass index (BMI), smoking status, blood pressure and retinopathy status was collected from the NDR. We considered the neuropathy variable in NDR as insufficient, and therefore chose to use retinopathy as a proxy variable instead.

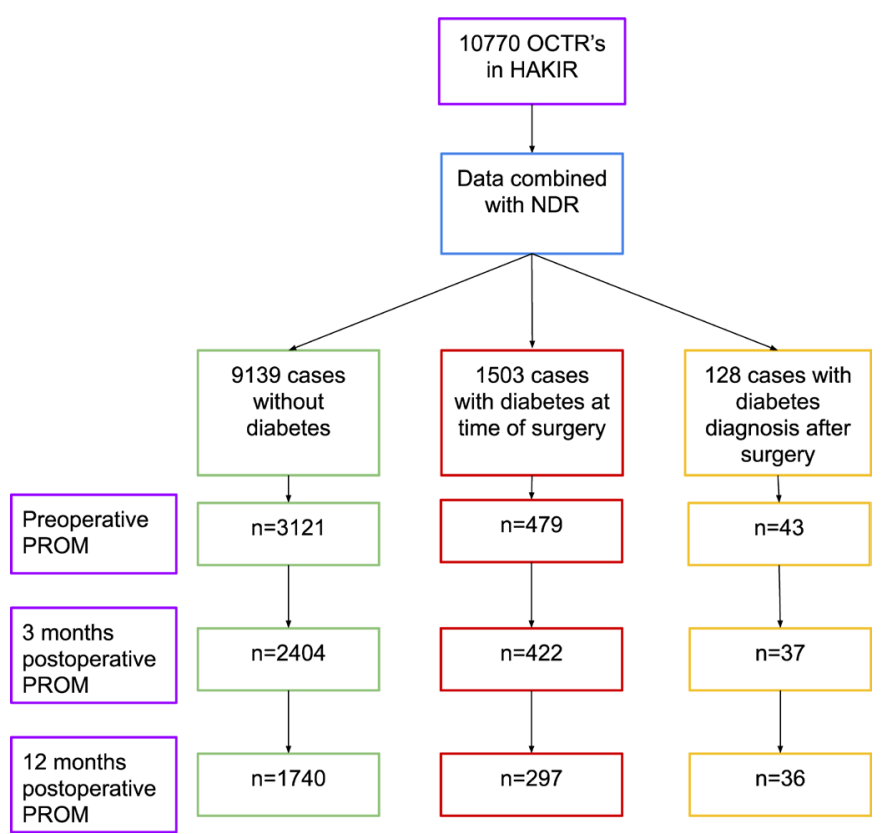

Figure 1 Flowchart describing the process of combining data from HAKIR and NDR. HAKIR, Swedish National Quality Registry for Hand Surgery; NDR, National Diabetes Register; OCTR, Open Carpal Tunnel Release; PROM,patient-reported outcome measure.

To identify patients with diabetes the data from HAKIR (2010-2016) was linked through personal identifying numbers of the patients to NDR data (1996-2016). There were 9139 cases without diabetes and 1503 cases with diabetes. Patients who were diagnosed with diabetes after the OCTR $(n=128)$ were analysed separately (figure 1$)$. Data on BMI, smoking status, blood pressure and all diabetes related variables were only available for the patients registered in NDR (ie, the patients with diabetes).

\section{Statistical methods}

Data are presented as median (IQR; Q25-Q75) if not otherwise stated. A Mann-Whitney test was used to compare differences between groups, with subsequent Bonferroni correction for multiple testing when indicated. Nominal data are presented as numbers (percent) and a $\chi^{2}$ test was used to compare differences between groups for dichotomous variables. Multivariate linear regression models were used to assess the effect on individual variables on postoperative QuickDASH total scores while controlling for observed gender and age differences between groups. We used directed acyclic graph model $^{27}$ to illustrate possible confounders and to choose variables for the regression analysis (online supplemental figure 1). In the first model, using postoperative QuickDASH scores at (1) 3 months and (2) 12 months as outcome measure, we included the following covariates: gender, age at surgery and diabetes. The second linear regression model was designed to investigate the effect of HbA1c levels on QuickDASH scores at (1) preoperatively, (2) 3 months postoperatively and (3) 12 months postoperatively, adjusted for age at surgery and gender. 
Table 1 Caracteristics and QuickDASH scores in patients with diabetes compared with patients without diabetes before and after open carpal tunnel release

\begin{tabular}{|c|c|c|c|c|c|c|}
\hline & $\begin{array}{l}\text { No diabetes } \\
(n=9267)\end{array}$ & $\begin{array}{l}\text { Diabetes } \\
(n=1503)\end{array}$ & $P$ value & $\begin{array}{l}\text { Diabetes diagnosed } \\
\text { postoperatively } \\
(n=128)\end{array}$ & $\begin{array}{l}\text { P value } \\
\text { (compared } \\
\text { with no } \\
\text { diabetes) }\end{array}$ & $\begin{array}{l}\text { All } \\
(n=10770)\end{array}$ \\
\hline Female, n (\%) & $6320(68 \%)$ & 850 (57\%) & $<0.0001$ & 80 (63\%) & 0.053 & 7170 (67\%) \\
\hline $\begin{array}{l}\text { Age at surgery } \\
\text { (years) }\end{array}$ & $54(43-67)$ & $63(53-74)$ & $<0.0001$ & $60(50-68)$ & 0.001 & $56(44-68)$ \\
\hline $\begin{array}{l}\text { Total DASH } \\
\text { preoperative }\end{array}$ & $\begin{array}{l}50(34-66) \\
(n=3121)\end{array}$ & $\begin{array}{l}55(37-71) \\
(n=479)\end{array}$ & 0.001 & $59(45-68)(n=43)$ & 0.029 & $\begin{array}{l}52(34-66) \\
(n=3600)\end{array}$ \\
\hline $\begin{array}{l}\text { Total DASH } 3 \text { months } \\
\text { postoperative }\end{array}$ & $\begin{array}{l}21(9-41) \\
(n=2404)\end{array}$ & $\begin{array}{l}27(14-50) \\
(n=422)\end{array}$ & $<0.0001$ & $43(7-53)(n=37)$ & 0.178 & $\begin{array}{l}23(10-39) \\
(n=2790)\end{array}$ \\
\hline $\begin{array}{l}\text { Total DASH } \\
12 \text { months } \\
\text { postoperative }\end{array}$ & $\begin{array}{l}16(5-38) \\
(n=1740)\end{array}$ & $20(7-43)(n=297)$ & 0.013 & $35(10-56)(n=36)$ & 0.005 & $\begin{array}{l}16(5-34) \\
(n=2002)\end{array}$ \\
\hline $\begin{array}{l}\text { Change in total } \\
\text { QuickDASH score } \\
0-12 \text { months }\end{array}$ & $\begin{array}{l}27(14-41) \\
(n=739)\end{array}$ & $\begin{array}{l}25(11-39) \\
(\mathrm{n}=115)\end{array}$ & 0.263 & $17(6-33)(n=12)$ & 0.164 & $\begin{array}{l}25(11-40) \\
(n=842)\end{array}$ \\
\hline
\end{tabular}

Data presented as median (IQR) or number (\%).

In the third regression model, we investigated the effect of smoking in patients with diabetes on postoperative QuickDASH scores at (1) 3 months postoperative and (2) 12 months postoperative. B-coefficients are unstandardised. Comparisons between individual HQ-8 items were done with independent samples t-test. We assumed that hands were statistically independent units and that drop-outs were random. We analysed gender and age in patients lost to follow-up. A $p$ value of $<0.05$ was considered statistically significant. All calculations were made in SPSS Statistics, IBM V.24.

\section{Patient and public involvement}

We have collaboration, including information, lectures and dialogue, with patient organisations on a regular basis to get direct information about hand problems in individuals with diabetes. Such dialogue is the basis for our hypothesis concerning the diabetic hand, which includes the present condition, that is, CTS.

\section{RESULTS}

\section{Study population}

Baseline characteristics and QuickDASH scores are shown in table 1. In total, 10770 OCTRs were registered in HAKIR due to primary CTS during 2010-2016 and were included in the study (figure 1). During the study period, 1721 patients operated bilaterally for CTS were registered, that is, the study population consists of 10770 hands on 9049 patients. For the bilaterally operated patients, mean time from first surgery to second surgery was 105 days (95\% CI 98 to 113 days). QuickDASH results over time in the different groups are presented in figure 2.

\section{Follow-up}

Preoperative response rate for both QuickDASH and HQ-8 was $3600 / 10770$ (33\%), at 3 months postoperative $2686 / 10010(27 \%)$ and at 12 months postoperative 1973/8297 (24\%). Patients, who did not complete QuickDASH and HQ-8 at any occasion, were younger than patients who had filled in at least one questionnaire with median 54 years (IQR 43-67 years) compared with 57 years (IQR 46-69 years); $p<0.0001$. There was no difference in the gender distribution $(\mathrm{p}=0.49)$ between responders and non-responders. Non-responders scored higher on preoperative QuickDASH (median 52 (IQR $35-68)$ ) versus $48(32-64)(\mathrm{p}<0.0001)$.

\section{Diabetes}

Of the 10770 cases, 1503 (14\%) had diabetes at time of surgery (figure 1). For the distribution of the type of diabetes, 1150/1503 had type 2 diabetes, 335/1503 had type 1 diabetes, $6 / 1503$ had secondary diabetes and in $12 / 1503$ data on type of diabetes were missing. In the

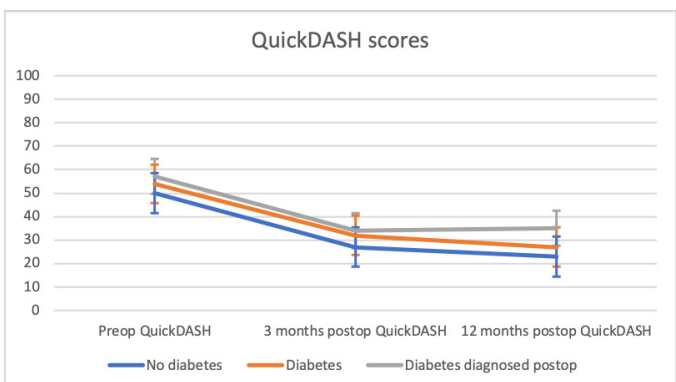

Figure 2 QuickDASH results (mean scores, error bars represent SE) over time in patients without diabetes, patients with diabetes and patients with diabetes diagnosed postoperatively. 


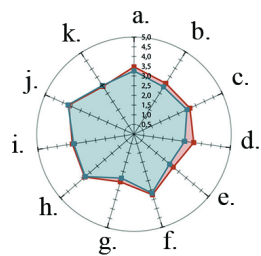

Preoperative

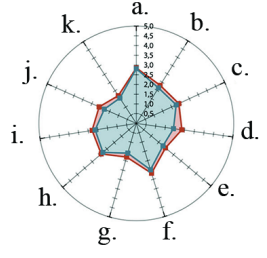

3 months postoperative

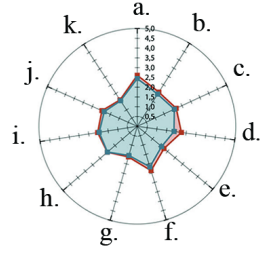

12 months postoperative
Diabetes

No diabetes

Figure 3 Individual QuickDASH items (mean) in patients with CTS without diabetes compared to patients with CTS and diabetes preoperative and at 3 and 12 months postoperative. (a) Opening a tight or new jar, (b) performing heavy household chores, (c) carrying a shopping bag/ briefcase, (d) washing your back, (e) using a knife to cut food, (f) recreational activities, (g) disturbed social activities, (h) disturbed work, (i) severity of pain, (j) severity of numbness/ paresthesia, (k) difficulty sleeping. CTS,carpal tunnel syndrome.

group of patients with diabetes, there were more men and they were older compared with the group without diabetes (table 1). The group with diabetes reported higher QuickDASH scores both before surgery and at 3 and 12 months after surgery (table 1, figure 3). There was no difference in the change in total score from 0 to 12 months between patients with diabetes and patients without diabetes.

Patients who received their diabetes diagnosis after surgery $(n=128)$ were older and reported statistically significant higher QuickDASH scores preoperatively and at 12 months postoperatively than patients without diabetes (table 1). Patients with diabetes diagnosed postoperatively had a smaller change in the QuickDASH score than patients without diabetes, however, not statistically significant (table 1).
When comparing type 1 diabetes and type 2 diabetes, the preoperative QuickDASH scores were statistically significant higher in the type 2 diabetes group compared with the type 1 diabetes group, but no statistically significant differences between the two groups were observed postoperatively (table 2 ). As expected, patients with type 2 diabetes were older, but did not differ concerning gender, and had a statistically significant higher BMI than the type 1 diabetes patients, their HbA1c levels were lower and their time since diagnosis of diabetes was shorter (table 2).

\section{Diabetes diagnosis at time of surgery}

In model 1 in the multivariate regression analysis, diabetes was associated with higher postoperative QuickDASH scores at 3 (B-coefficient 4.8, 95\% CI 2.5 to 7.1; p $<0.0001$, $\mathrm{n}=2826$ ) and 12 months (B-coefficient 3.0, 95\% CI 0.1 to 5.9; $\mathrm{p}=0.043, \mathrm{n}=2037$ ), adjusted for age and gender. This indicates that presence of diabetes is associated with 4.8 points higher QuickDASH scores at 3 months postoperative and 3.0 points higher QuickDASH scores at 12 months postoperative.

In model 2, preoperative HbAlc levels ( $\mathrm{mmol} / \mathrm{mol}$ ) were associated with postoperative QuickDASH scores at 3 (B-coefficient $0.25,95 \%$ CI 0.072 to $0.43 ; \mathrm{p}=0.004$, $\mathrm{n}=393$ ) and 12 months (B-coefficient $0.28,95 \%$ CI 0.076 to $0.48 ; \mathrm{p}=0.007$ ), adjusted for age and gender. There was no association between preoperative HbAlc levels and preoperative QuickDASH scores $(\mathrm{p}=0.28)$.

\section{Retinopathy}

The group of patients with diabetes and retinopathy was statistically significantly younger and a higher proportion of patients in this group had type 1 diabetes when compared with the group without retinopathy (table 3).

Table 2 Characteristics of type 1 diabetes (T1D) versus type 2 diabetes (T2D) patients operated due to carpal tunnel syndrome

\begin{tabular}{|c|c|c|c|}
\hline & T1D ( $n=335)$ & T2D $(n=1150)$ & $P$ value \\
\hline Female, n (\%) & $204(61)$ & $635(56)$ & 0.483 \\
\hline Age at surgery (years) & $49(38-58)$ & $67(57-76)$ & $<0.0001$ \\
\hline BMI & $26.3(23.4-30.2)$ & $30.5(27.6-34.5)$ & $<0.0001$ \\
\hline Current smoker, n (\%) & $24(7 \%)$ & $127(11 \%)$ & 0.024 \\
\hline $\mathrm{HbA} 1 \mathrm{c}(\mathrm{mmol} / \mathrm{mol})$ & $65(57-74)$ & $52(45-61)$ & $<0.0001$ \\
\hline Retinopathy, n (\%) & $221(67 \%)$ & $233(20 \%)$ & $<0.0001$ \\
\hline Systolic BP (mm Hg) & $125(115-135)$ & $134(125-140)$ & $<0.0001$ \\
\hline Diastolic BP (mm Hg) & $75(70-80)$ & $75(70-80)$ & 0.052 \\
\hline Duration of diabetes (years) & $28(18-38)$ & $8(3-15)$ & $<0.0001$ \\
\hline Total QuickDASH preoperative & $48(34-66)(n=111)$ & $57(38-70)(n=361)$ & 0.026 \\
\hline Total QuickDASH 3 months postoperative & $23(14-38)(n=85)$ & $28(14-52)(n=327)$ & 0.13 \\
\hline Total QuickDASH 12 months postoperative & $16(7-39)(n=66)$ & $23(7-45)(n=224)$ & 0.62 \\
\hline Change in total QuickDASH score 0-12 months & $26(12-36)(n=26)$ & $23(11-39)(n=86)$ & 0.86 \\
\hline
\end{tabular}

Numbers presented as median (IQR) or number (\%).

$\mathrm{BMI}$, bodymass index; BP, blood pressure. 
Table 3 Comparison between cases with retinopathy and CTS and cases without retinopathy and CTS

\begin{tabular}{|c|c|c|c|}
\hline & No retinopathy $(n=539)$ & Retinopathy ( $n=454)$ & $P$ value \\
\hline Female, n (\%) & $425(79)$ & $358(79)$ & 0.998 \\
\hline Age at surgery (years) & $65(56-74)$ & $59(48-72)$ & $<0.0001$ \\
\hline $\mathrm{BMI}$ & $30(27-34)$ & $29(26-33)$ & 0.030 \\
\hline Current smoker, n (\%) & $57(11)$ & $39(9)$ & 0.252 \\
\hline Duration of diabetes (years) & $8(4-14)$ & $22(13-33)$ & $<0.0001$ \\
\hline Total DASH preoperative & $57(39-73)(n=172)$ & $57(36-70)(n=154)$ & 0.373 \\
\hline Total DASH 3 months postoperative & $25(9-45)(n=143)$ & $32(16-55)(n=123)$ & 0.004 \\
\hline Total DASH 12 months postoperative & $21(5-43)(n=92)$ & $21(7-43)(n=88)$ & 0.495 \\
\hline Change in total QuickDASH score 0-12 months & $27(11-39)(n=38)$ & $25(12-35)(n=33)$ & 0.624 \\
\hline
\end{tabular}

BMI, bodymass index; CTS, carpal tunnel syndrome.

The group with retinopathy also had higher HbA1c and a longer duration of diabetes than the group without retinopathy. The only observed difference in QuickDASH scores was at 3 months postoperatively, where the group with retinopathy reported higher scores (table 3 ).

\section{Smoking and diabetes}

In the linear regression model 3, only including patients with diabetes, cigarette smoking increased the QuickDASH score at 12 months postoperatively with 12.7 points (95\% CI 2.96 to $22.43 ; p=0.011)$. Older age at surgery in patients with diabetes was also associated to higher postoperative QuickDASH scores at 12 months (B-coefficient 0.33 (95\% CI 0.13 to $0.54 ; \mathrm{p}=0.002)$.

\section{Individual HQ-8 questions}

Distribution of answers to the individual HQ-8 questions are presented in figure 4 and in detail in online supplementary table 1 . Patients with diabetes scored higher at baseline on stiffness and weakness compared with patients without diabetes. At 3 months postoperatively, patients with diabetes scored higher on pain on motion without load, pain at rest, stiffness, numbness/tingling in fingers and ability to perform daily activities. At 12 months postoperatively, patients with diabetes scored higher on pain on motion without load.

\section{DISCUSSION}

This study, evaluating a large number of patients with CTS from linking two nationwide registries, indicates, as has been previously reported, ${ }^{11} 28$ that patients with diabetes experience more symptoms both before and after OCTR. The differences between patients with and without diabetes in perceived disability using the QuickDASH were small and might not be clinically relevant. The relative improvement following surgery was, however, the same between the two groups. Most of the improvement after surgery was seen during the first 3 months. Additional improvement was seen between 3 and 12 months, indicating that the final result after OCTR should not be evaluated too early. The initial improvement after OCTR can be explained by reestablishment of the microcirculation
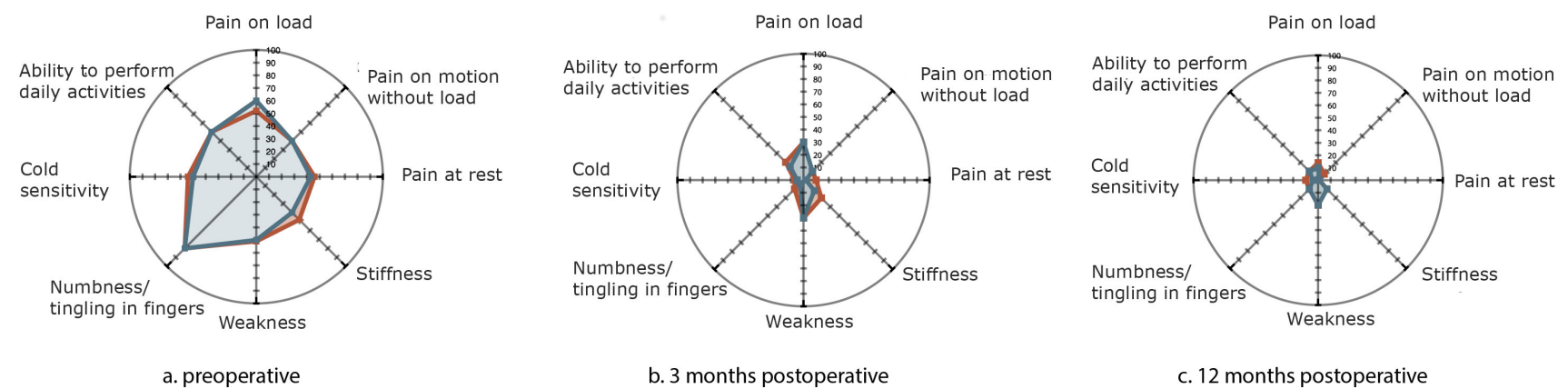

Figure $4 \mathrm{HQ}-8$ questions (median) in patients with CTS without diabetes compared with patients with CTS and diabetes preoperative and at 3 and 12 months postoperative. CTS,carpal tunnel syndrome; HQ-8, HAKIR questionnaire-8. 
in the nerve and probably also a remyelination of demyelinated nerve fibres. The long-term improvement on the other hand might be due to regeneration and remyelination of damaged axons, which may last even in patients with diabetes up to 5 years. ${ }^{3}$

In the group of patients with diabetes, the male proportion was higher than in the group of patients without diabetes. It has earlier been shown that diabetic neuropathy develops earlier in men than in women, ${ }^{29}$ which might be an explanation to the observed difference.

Cold sensitivity has earlier been shown to differ between patients with diabetes and patients without diabetes at 1 year after surgery, ${ }^{30}$ but the difference had disappeared at 5 years after surgery. ${ }^{3}$ We could not demonstrate any differences up to 12 months after surgery using a similar Likert scale. The pathophysiology for cold sensitivity in diabetes is not yet fully understood, but pain thresholds for cold are lower in extremities that have suffered a nerve damage. ${ }^{31}$

In patients with diabetes, higher preoperative $\mathrm{HbA1c}$ levels were associated with higher postoperative QuickDASH scores. In the diabetes control and complications trial/epidemiology of diabetes interventions and complications (DCCT/EDIC) study on patients with type 1 diabetes, disabilites of arm, shoulder and hand (DASH) scores were associated with HbAlc levels. ${ }^{32}$ Hence, it seems like an intensive glucose control can enhance postoperative outcomes after OCTR.

We found that patients with retinopathy, which could be considered as a proxy variable for microvascular diabetes complications, and hence for neuropathy, reported higher QuickDASH scores at 3 months postoperative, but that the difference disappeared at 12 months postoperative. Considering the strong association between retinopathy changes and diabetic neuropathy, ${ }^{14}{ }^{15}$ one possible explanation could be that the nerves of patients with retinopathy are affected by metabolic factors. Therefore, they might need longer time to recover after decompression surgery, considering the difference in regeneration capacity in diabetes after nerve injury and repair. ${ }^{33}$ In addition, there is an association between presence of corneal neuropathy, evaluated by corneal confocal microscopy, and loss of intraepidermal nerve fibre density in skin biopsies, that is, unmyelinated nerve fibres. ${ }^{17}$ Corneal confocal microscopy is emerging as a new non-invasive technique of assessing neuropathy in diabetes patients. However, one should consider that larger myelinated nerve fibres are more susceptible to nerve compression than thinner myelinated nerve fibres, while unmyelinated nerve fibres are resistant to compression. ${ }^{34}$ CTS might be more common in patients with retinopathy, since retinopathy is associated with longer duration of diabetes. Retinopathy is also more common in patients with type 1 diabetes. In our cohort, type 1 diabetes was more common (23\%) than in a normal population $(\sim 10 \%) \cdot{ }^{35}$ In this study, $46 \%$ of patients with diabetes had retinopathy (although data on retinopathy status were missing in about $1 / 3$ of patients with diabetes). In the annual report from NDR in $2018,{ }^{35} 28 \%$ of patients treated in primary care, $59 \%$ of type 2 diabetes patients treated at hospital clinics and $68 \%$ of type 1 diabetes patients treated at hospital clinics have diabetic retinopathy.

The group that did not have diabetes at the time of surgery, but that received a diabetes diagnosis during the study period, had worse surgery outcome than the group without diabetes. They also reported more disability in the QuickDASH compared with the patients who had a diabetes diagnosis at the time of surgery. In the UK Prospective Diabetes Study and in a Finnish study, the prevalence of peripheral neuropathy was $7 \%$ and $8 \%$, respectively, at the time of diabetes diagnosis,${ }^{36}{ }^{37}$ suggesting that diabetic complications may well be present even before the disease is diagnosed. When studying structural changes in the posterior interosseous nerve located at the same level as the compressed median nerve in patients with CTS, pathology is more severe in patients with diabetes compared with patients without diabetes. ${ }^{38} 39$ This suggests that subclinical structural changes in the diabetic nerve may confer an increased susceptibility to compression. ${ }^{40}$ Theoretically, CTS could be the first presenting symptom in diabetes, but screening patients for diabetes when presenting with CTS has not been shown to be a cost-effective option. ${ }^{41}$

Diabetic hand problems might interfere with the results in QuickDASH and HQ-8 for patients with diabetes, even if older men with type 2 diabetes experience minor problems in daily life. ${ }^{42}$ None of these questionnaires is disease-specific for CTS, but DASH has been compared with the Boston Carpal Tunnel Questionnaire, and found to be reliable to evaluate CTS. ${ }^{43}$ QuickDASH is not designed for individual analysis of separate items. The HQ-8, on the other hand, allows for analysis of separate items. In both questionnaires, as illustrated in the figures, CTS-related symptoms improved in both groups. In HQ-8, patients with diabetes reported more persistent numbness/paresthesia 3 months after surgery than patients without diabetes, again, suggesting that an underlying neuropathy may contribute to the remaining described symptoms. In a previous study, we found that results of electrophysiology testing were worse in patients with diabetes. ${ }^{10}$ It is possible that patients with diabetes are operated earlier than patients without diabetes, since they already have an established contact with the healthcare system. On the other hand, CTS symptoms might be misinterpreted as general diabetic neuropathy symptoms in patients with diabetes; hence, with a delayed time to surgery.

Patients with diabetes experienced more stiffness, as earlier described. ${ }^{42}{ }^{44}$ Stiffness may be due to limited joint motion and/or mild Dupuytren's contracture, ${ }^{45}$ as part of the diabetic hand. ${ }^{46}$ When discussing improvement after surgery using PROMs, a minimal clinically important difference (MCID) is often used. However, there is no consensus on the MCID in QuickDASH for CTS. $^{47}$ Among previous published research on this matter, our population mostly resembles the population 
used by Smith-Forbes, suggesting a MCID of 18.7 points. ${ }^{48}$ Both the present patients with and without diabetes had a median change of more than 18.7 points in the QuickDASH after OCTR; thus, the differences observed between patients with and without diabetes might not be clinically relevant.

Even though small numbers, patients with type 1 diabetes reported similar outcome as patients with type 2 diabetes, despite longer duration of diabetes, higher prevalence of retinopathy and higher HbA1c levels. Neuropathy in peripheral nerves is more severe in type 1 diabetes than in type 2 diabetes, ${ }^{49}$ which would indicate a higher risk for developing CTS and for an unfavourable outcome. However, QuickDASH scores were higher in the type 2 diabetes patients before surgery, indicating worse symptoms of CTS. One possible explanation to the noted differences in QuickDASH could be that the type 2 diabetes patients were much older than patients with type 1 diabetes, since age was associated with higher QuickDASH scores postoperatively; again, the reason could be structural changes in the peripheral nerves. ${ }^{50}$ It is also possible that older patients have other hand conditions, such as CMC1 arthritis or Dupuytrens, that affect their QuickDASH results.

We confirm in this study that cigarette smoking is associated with greater persistent disability following OCTR in patients with diabetes. Therefore, it is advisable for patients with CTS, particularly those with diabetes, to quit smoking before surgery in order to improve postoperative results. It is also known that both smoking and diabetes increase the risk of postoperative infection..$^{51}$ Thus, when treating patients who smoke or patients with diabetes, or both, the surgeon should inform the patient about the risk of complications and residual symptoms.

In big registries, there is always a risk of incorrect coding. However, in a parallel study of ulnar nerve pathology, using data from HAKIR where we also reviewed the patients' medical files, only $12 / 556$ cases $(2.2 \%)$ were incorrectly coded (unpublished data).

\section{CONCLUSION}

In conclusion, in this large study on patient-reported outcome after OCTR patients with diabetes generally benefitted from surgery, but did not gain equivalent symptom resolution as patients without diabetes. Patients with retinopathy, as a proxy for neuropathy, may need longer time for symptoms to resolve after OCTR. Smoking, older age, higher HbAlc levels and receiving a diabetes diagnosis after surgery are associated with more residual symptoms following OCTR.

\footnotetext{
Author affiliations

${ }^{1}$ Department of Translational Medicine - Hand Surgery, Lund University, Lund, Sweden

${ }^{2}$ Department of Hand Surgery, Skånes universitetssjukhus Malmö, Malmo, Sweden

${ }^{3}$ Department of Medicine, University of Gothenburg, Göteborg, Sweden

${ }^{4}$ Department of Medicine, Sahlgrenska University Hospital, Goteborg, Sweden
}

${ }^{5}$ National Diabetes Register, Centre of Registers in Region Västra Götaland, Gothenburg, Sweden

${ }^{6}$ Department of Data Analytics and Register Centre, Region Skåne Hälso- och sjukvård, Lund, Sweden

${ }^{7}$ HAKIR, National Registry for Hand Surgery, Stockholm South General Hospital, Stockholm, Sweden

${ }^{8}$ Department of Clinical Science and Education Södersjukhuset, Karolinska Institutet, Stockholm, Sweden

Acknowledgements The authors thank the regional NDR and HAKIR coordinators as well as the contributing nurses, physicians and patients. We are very grateful to Tina Folker for her administrative help.

Contributors MZ did the calculations and wrote the draft of the manuscript. KE- 0 and A-MS contributed to acquisition and interpretation of the data from NDR. MÅ revised data analysis and interpretations. MA acquired data from HAKIR. LD designed the study and contributed to interpretations. All authors contributed to data interpretation, the article draft and revision of the paper. All authors have approved the final version of the manuscript.

Funding This work was supported by grants from the Lund University, the Swedish Diabetes Foundation, Sydvästra Skånes Diabetesförening and Region Skåne (Skåne University Hospital Malmö-Lund), Sweden. The study sponsors were not involved in the design of the study; the collection, analysis, and interpretation of data; writing the report; or the decision to submit the report for publication.

\section{Competing interests None declared.}

Patient and public involvement statement Patients were not directly involved in the design and conception of this study.

Patient consent for publication Not required.

Ethics approval The study protocol has been approved by the Regional Ethical Review Boards in Lund and Stockholm, Sweden, Dnr 2016/931 and Dnr 2017/2023-31.

Provenance and peer review Not commissioned; externally peer reviewed.

Data availability statement Data may be obtained from a third party and are not publicly available.

Open access This is an open access article distributed in accordance with the Creative Commons Attribution Non Commercial (CC BY-NC 4.0) license, which permits others to distribute, remix, adapt, build upon this work non-commercially, and license their derivative works on different terms, provided the original work is properly cited, appropriate credit is given, any changes made indicated, and the use is non-commercial. See: http://creativecommons.org/licenses/by-nc/4.0/.

\section{REFERENCES}

1. Geoghegan JM, Clark DI, Bainbridge LC, et al. Risk factors in carpal tunnel syndrome. J Hand Surg Am 2004;29:315-20.

2. Jansen MC, Evers S, Slijper HP, et al. Predicting Clinical Outcome After Surgical Treatment in Patients With Carpal Tunnel Syndrome. J Hand Surg Am 2018;43:1098-106.

3. Thomsen NOB, Andersson GS, Björk J, et al. Neurophysiological recovery 5 years after carpal tunnel release in patients with diabetes. Muscle Nerve 2017;56:E59-E64.

4. Watchmaker JD, Watchmaker GP. Independent variables affecting outcome of carpal tunnel release surgery. Hand 2017:1558944717703739.

5. Cagle PJ, Reams M, Agel J, et al. An outcomes protocol for carpal tunnel release: a comparison of outcomes in patients with and without medical comorbidities. J Hand Surg Am 2014;39:2175-80.

6. Ozkul Y, Sabuncu T, Kocabey Y, et al. Outcomes of carpal tunnel release in diabetic and non-diabetic patients. Acta Neurol Scand 2002;106:168-72.

7. Jenkins PJ, Duckworth AD, Watts AC, et al. The outcome of carpal tunnel decompression in patients with diabetes mellitus. J Bone Joint Surg Br 2012;94-B:811-4.

8. Isik C, Uslu M, Inanmaz ME, et al. The effects of diabetes on symptoms of carpal tunnel syndrome treated with mini-open surgery. Acta Orthop Belg 2013;79:381-5.

9. Zyluk A, Puchalski P. A comparison of outcomes of carpal tunnel release in diabetic and non-diabetic patients. $J$ Hand Surg Eur Vol 2013;38:485-8.

10. Dahlin E, Zimmerman M, Björkman A, et al. Impact of smoking and preoperative electrophysiology on outcome after open carpal tunnel release. J Plast Surg Hand Surg 2017;51:329-35. 
11. Zimmerman M, Dahlin E, Thomsen NOB, et al. Outcome after carpal tunnel release: impact of factors related to metabolic syndrome. $J$ Plast Surg Hand Surg 2017;51:165-71.

12. Rota E, Morelli N. Entrapment neuropathies in diabetes mellitus. World J Diabetes 2016;7:342-53.

13. Tapadia M, Mozaffar T, Gupta R. Compressive neuropathies of the upper extremity: update on pathophysiology, classification, and electrodiagnostic findings. J Hand Surg Am 2010;35:668-77.

14. Pemp B, Palkovits S, Howorka K, et al. Correlation of retinal neurodegeneration with measures of peripheral autonomic neuropathy in type 1 diabetes. Acta Ophthalmol 2018;96:e804-10.

15. Bjerg L, Hulman A, Charles M, et al. Clustering of microvascular complications in type 1 diabetes mellitus. J Diabetes Complications 2018;32:393-9.

16. De Clerck EEB, Schouten JSAG, Berendschot TTJM, et al. New ophthalmologic imaging techniques for detection and monitoring of neurodegenerative changes in diabetes: a systematic review. Lancet Diabetes Endocrinol 2015;3:653-63.

17. Jiang M-S, Yuan Y, Gu Z-X, et al. Corneal confocal microscopy for assessment of diabetic peripheral neuropathy: a meta-analysis. $\mathrm{Br} \mathrm{J}$ Ophthalmol 2016;100:9-14.

18. Arner M. Developing a national quality Registry for hand surgery: challenges and opportunities. EFORT Open Rev 2016:1:100-6.

19. HAKIR. Annual report; 2016.

20. Abercrombie M, Johnson ML. Collagen content of rabbit sciatic nerve during Wallerian degeneration. Journal of Neurology, Neurosurgery \& Psychiatry 1946;9:113-8.

21. Institute for Work and Health. Scoring the QuickDASH; 2016.

22. Socialstyrelsen. Klassifikationer av kirurgiska åtgärder 1997 (KKÅ); 2004.

23. World Health Organization. The International statistical classification of diseases and related health problems 10th revision; 1993.

24. NDR. NDR Swedish national diabetes register. Available: www.ndr.nu

25. Lind M, Bounias I, Olsson M, et al. Glycaemic control and incidence of heart failure in 20985 patients with type 1 diabetes: an observational study. The Lancet 2011;378:140-6.

26. Eliasson B, Gudbjörnsdottir S. Diabetes care--improvement through measurement. Diabetes Res Clin Pract 2014;106 Suppl 2:S291-S294.

27. Shrier I, Platt RW. Reducing bias through directed acyclic graphs. BMC Med Res Methodol 2008;8:70.

28. Turner A, Kimble F, Gulyás K, et al. Can the outcome of open carpal tunnel release be predicted?: a review of the literature. ANZ J Surg 2010;80:50-4.

29. Aaberg ML, Burch DM, Hud ZR, et al. Gender differences in the onset of diabetic neuropathy. J Diabetes Complications 2008;22:83-7.

30. Thomsen NOB, Cederlund R, Rosén I, et al. Clinical outcomes of surgical release among diabetic patients with carpal tunnel syndrome: prospective follow-up with matched controls. $J$ Hand Surg Am 2009;34:1177-87.

31. Kalliomäki M, Kieseritzky JV, Schmidt R, et al. Structural and functional differences between neuropathy with and without pain? Exp Neurol 2011;231:199-206.

32. Larkin ME, Barnie A, Braffett BH, et al. Musculoskeletal complications in type 1 diabetes. Diabetes Care 2014;37:1863-9.

33. Stenberg L, Dahlin LB. Gender differences in nerve regeneration after sciatic nerve injury and repair in healthy and in type 2 diabetic GotoKakizaki rats. BMC Neurosci 2014;15:107.
34. Dahlin LB, Shyu BC, Danielsen N, et al. Effects of nerve compression or ischaemia on conduction properties of myelinated and non-myelinated nerve fibres. An experimental study in the rabbit common peroneal nerve. Acta Physiol Scand 1989;136:97-105.

35. NDR. Swedish national diabetes register. Available: www.ndr.nu2018

36. Bjurholm A. Neuroendocrine peptides in bone. Int Orthop 1991;15:325-9.

37. Partanen J, Niskanen L, Lehtinen J, et al. Natural history of peripheral neuropathy in patients with non-insulin-dependent diabetes mellitus. N Engl J Med 1995;333:89-94.

38. Thomsen NOB, Mojaddidi M, Malik RA, et al. Reduced myelinated nerve fibre and endoneurial capillary densities in the forearm of diabetic and non-diabetic patients with carpal tunnel syndrome. Acta Neuropathol 2009:118:785-91.

39. Mojaddidi MA, Ahmed MS, Ali R, et al. Molecular and pathological studies in the posterior interosseous nerve of diabetic and nondiabetic patients with carpal tunnel syndrome. Diabetologia 2014:57:1711-9.

40. Mulder DW, Lambert EH, Bastron JA, et al. The neuropathies associated with diabetes mellitus. A clinical and electromyographic study of 103 unselected diabetic patients. Neurology 1961;11(4)Pt $1: 275-84$

41. de Rijk MC, Vermeij FH, Suntjens M, et al. Does a carpal tunnel syndrome predict an underlying disease? Journal of Neurology, Neurosurgery \& Psychiatry 2007;78:635-7.

42. Cederlund RI, Thomsen N, Thrainsdottir S, et al. Hand disorders, hand function, and activities of daily living in elderly men with type 2 diabetes. J Diabetes Complications 2009;23:32-9.

43. Greenslade JR, Mehta RL, Belward P, et al. Dash and Boston questionnaire assessment of carpal tunnel syndrome outcome: what is the responsiveness of an outcome questionnaire? J Hand Surg Am 2004;29:159-64.

44. Chammas M, Bousquet P, Renard E, et al. Dupuytren's disease carpal tunnel syndrome, trigger finger, and diabetes mellitus. $J$ Hand Surg 1995;20A:109-14.

45. Rosenbloom AL. Limited joint mobility in childhood diabetes: discovery, description, and decline. J Clin Endocrinol Metab 2013;98:466-73.

46. Papanas N, Maltezos E. The diabetic hand: a forgotten complication? J Diabetes Complications 2010;24:154-62.

47. Rodrigues JN, Mabvuure NT, Nikkhah D, et al. Minimal important changes and differences in elective hand surgery. $J$ Hand Surg Eur Vol 2015;40:900-12.

48. Smith-Forbes EV, Howell DM, Willoughby J, et al. Specificity of the minimal clinically important difference of the quick disabilities of the arm shoulder and hand (QDASH) for distal upper extremity conditions. J Hand Ther 2016;29:81-8.

49. Osman AAM, Dahlin LB, Thomsen NOB, et al. Autophagy in the posterior interosseous nerve of patients with type 1 and type 2 diabetes mellitus: an ultrastructural study. Diabetologia 2015;58:625-32.

50. Mohseni S, Badii M, Kylhammar A, et al. Longitudinal study of neuropathy, microangiopathy, and autophagy in sural nerve: implications for diabetic neuropathy. Brain Behav 2017;7:e00763.

51. Werner BC, Teran VA, Deal DN. Patient-Related risk factors for infection following open carpal tunnel release: an analysis of over 450,000 Medicare patients. J Hand Surg Am 2018;43:214-9. 